\title{
An objective clinical study of chest expansion
}

\author{
J. M. H. MOLL* AND V. WRIGHT $\dagger$
}

From the Rheumatism Research Unit, University Department of Medicine, the General Infirmary at Leeds, and the Royal Bath Hospital, Harrogate

Rigidity of the thoracic cage as a characteristic feature of ankylosing spondylitis has been recognized for over 250 years since the classical description by Bernard Connor in 1691 (Hartung, 1954).

The generally accepted importance of this sign is evidenced by its inclusion by two recent international symposia as a major criterion for the diagnosis of ankylosing spondylitis (Kellgren, Jeffrey, and Ball, 1963; Bennett and Wood, 1968). However, considering the significance of chest expansion as a useful measure of disease, not only in ankylosing spondylitis but also in chest disorders, it is surprising that no previous objective work to assess the normal range of this movement has been reported. Despite the lack of such objective chest data, recent attempts to quantify chest expansion by international agreement (Bennett and Wood, 1968) have resulted in the arbitrary definition of $2.5 \mathrm{~cm}$. as the borderline between normal and abnormal expansion. As a result of an objective clinical study of chest expansion in a large group of normal subjects, we have attempted to demonstrate the biological unreality of this inflexible and arbitrary definition. In addition, attention has been drawn to the importance of regarding chest expansion in terms of a widely varying normal range of values, significantly influenced by age and sex, and also by diseases other than spondylitis.

\section{Clinical material}

Chest expansion has been measured in two populations:

(a) A group of 262 'normal' subjects (111 males and 151 females) in order to establish a normal range of expansion. The subjects were obtained from a total unselected survey of three institutions chosen to provide a reasonably balanced number of males and females in each age group. The 'normal' population was composed, therefore, of the following:

(i) Boys and girls from Matthew Murray Comprehensive School, Leeds;

(ii) Male and female domestic staff, The General Infirmary, Leeds;

(iii) Male and female residents of Manor Grange Old People's Home, Leeds.

The 'normality' of this population is evidenced by the Gaussian distribution of the measurements in all three planes of expansion (circumferential, antero-posterior, and transverse) as shown in Figs 1, 2, and 3.
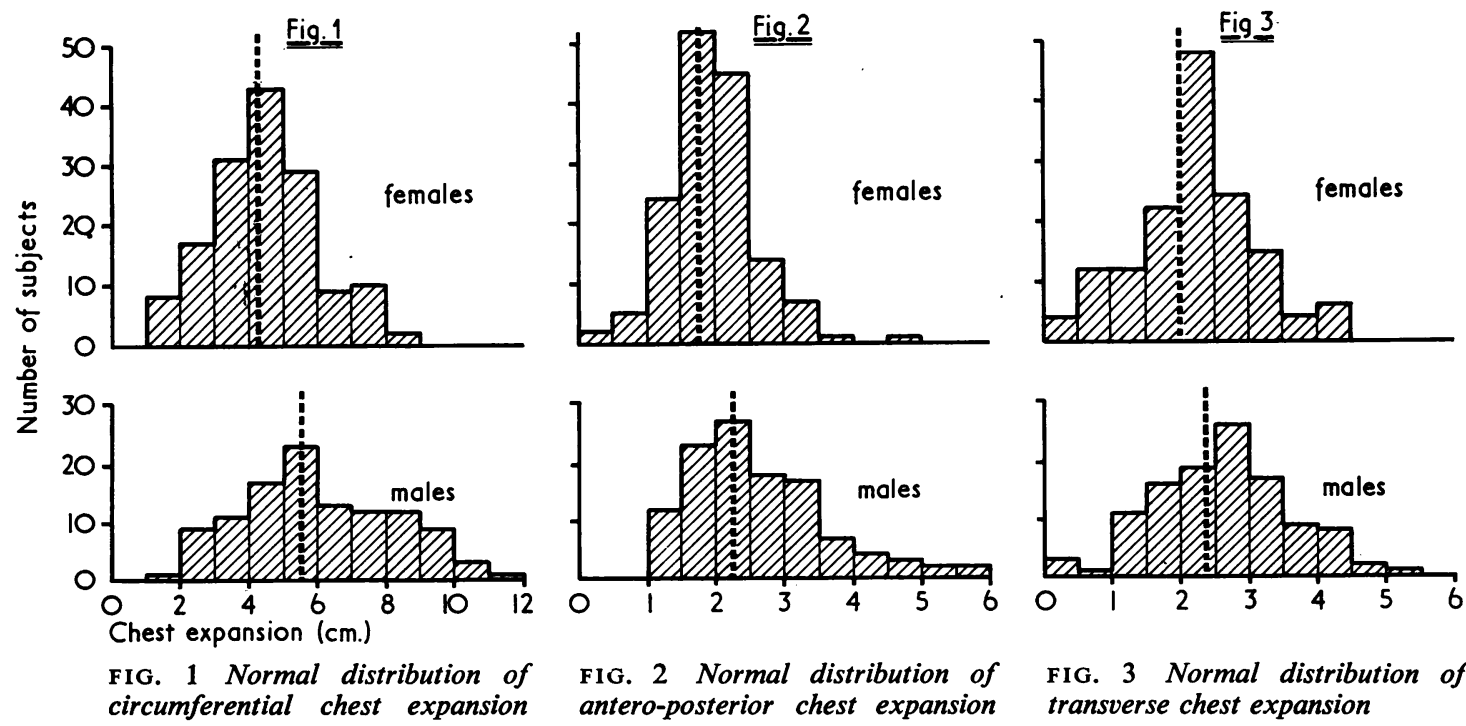

FIG. 2 Normal distribution of antero-posterior chest expansion

FIG. 3 Normal distribution of transverse chest expansion

Accepted for publication July 27, 1971. * Senior Registrar in Rheumatology, Oxford Regional Hospital Board (lately Research Assistant, Rheumatism Research Unit, University of Leeds).
† Professor of Rheumatology, University of Leeds.

Presented at a meeting of the Heberden Society in Belfast on September 17, 1971. 
(b) Three abnormal groups consisting of:

(i) 37 patients with 'definite' ankylosing spondylitis (New York criteria);

(ii) 31 patients with chronic chest disease-the majority being cases of chronic bronchitis and emphysema based on clinical and radiological evidence;

(iii) 33 excessively obese subjects, defined as patients in whom the weight was 20 per cent. above the desirable level (Craddock, 1969).

\section{Methods}

Chest expansion was measured circumferentially with a centimetre tape and diametrically (antero-posteriorly and transversely) by means of a specially designed caliper. Observations were carried out in three planes in order to examine the possibility of a differential pattern of expansion between different planes of movement in both normal subjects and also subjects with various diseases (ankylosing spondylitis, chest disease and obesity). The caliper measurements also provided an accurate objective parameter with which to compare the tape-measurements.

All observations were made on subjects unclad to the waist, standing with hands on head and arms flexed in the frontal plane (Fig. 4).

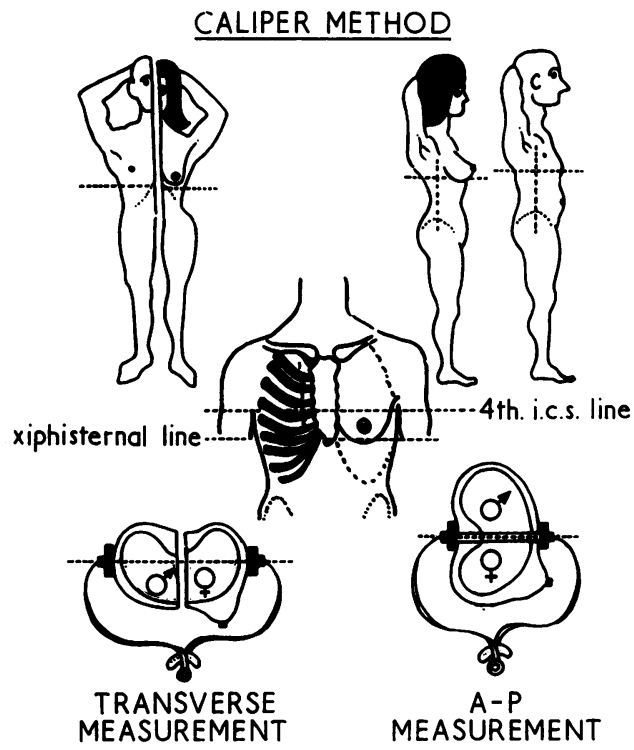

FIG. 4 Posture and landmarks for chest expansion measurements

The advantages of this arm-elevated posture are as follows:

(1) Maximal contraction of the main shoulder adductors is prevented, thus obviating a frequent tendency, often observed in young males, to exaggerate 'expansion' by strong voluntary contraction of these muscles-particularly the latissimus dorsi. A schematic representation of this artefact is shown in Fig. 5.

(2) The scapula and breasts are often lifted clear of the line of measurement.
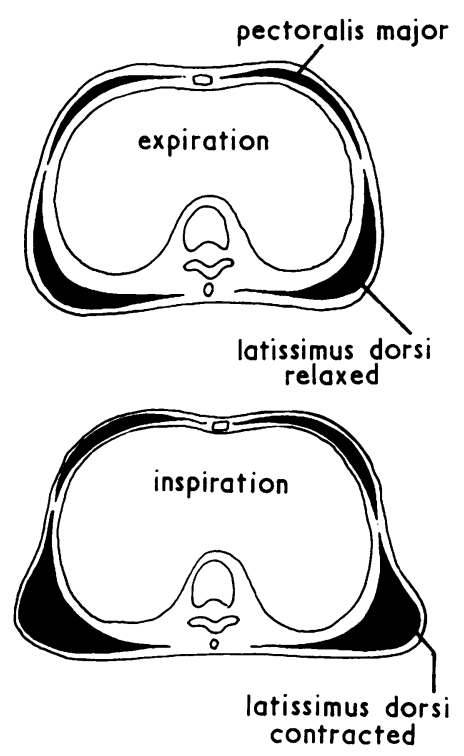

FIG. 5 Diagram showing how contraction of latissimus dorsi (and to a lesser extent pectoralis major) may exaggerate measurement of chest expansion (adapted from Wood Jones, 1946)

(3) The field of measurement is more readily observed.

(4) Application of the tape-measure and caliper blades considerably easier in this position.

Tape-measure method

Circumferential mobility was assessed by means of a $\overrightarrow{\vec{F}}$ conventional centimetre tape-measure at the level of the $\frac{3}{3}$ 4th intercostal space (Fig. 4), as recommended by the New York symposium (Bennett and Wood. 1968). Measurements were taken at the height of maximal inspiration and expiration and considerable care was exercised not to pull the tape too tightly while making the measurements. The observations were always preceded by 3 detailed instructions and, more important, by a personal demonstration of what was required, as subjects varied 0 immensely in their interpretation of the meaning of deep breathing.

\section{Caliper method}

The caliper consisted of a modified Breisky pelvimeter (Fig. 6). The modifications comprised:

(i) Mobile jointed contact units to facilitate application of $\mathrm{N}$ the caliper blades in thin subjects and to prevent undue N 'dimpling' in obese individuals;

(ii) A light-weight spring to enable constant tension to be transmitted to the caliper blades;

(iii) Improved accuracy of the caliper scale (which was $\stackrel{\oplus}{+}$ calibrated to the nearest $0.25 \mathrm{~cm}$.).

Measurements in inspiration and expiration were $\frac{0}{\overrightarrow{0}}$

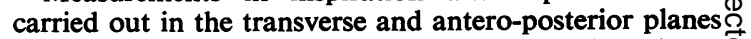
(Fig. 4) at the level of the xiphisternal junction in order to $\mathbb{Q}$ eliminate as far as possible the breasts and lateral chest muscles from the field of measurement. 


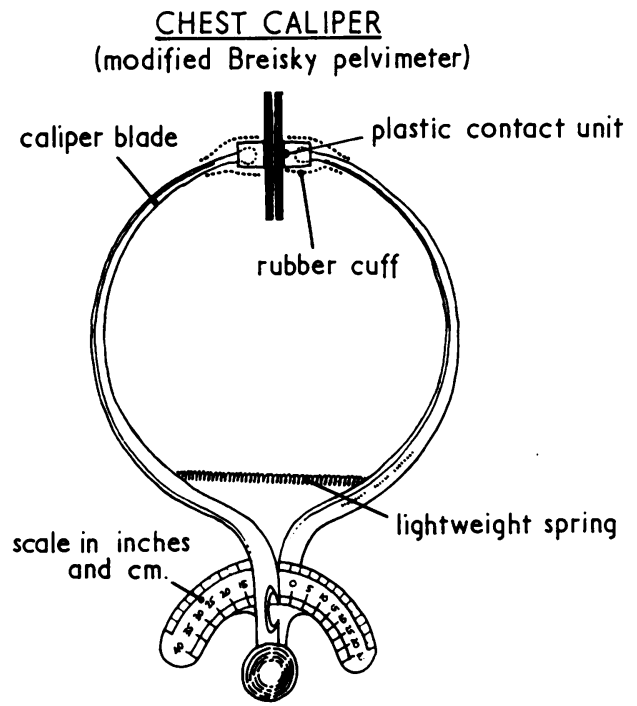

FIG. 6 Details of chest caliper (modified Breisky pelvimeter).

\section{Results}

(1) CHEST EXPANSION IN NORMAL SUBJECTS For each plane of measurement a range of normal values was established (Tables I, II, and III). The following observations deserve particular emphasis:

(a) Mean expansion followed a similar trend in both sexes whether measured circumferentially, anteroposteriorly, or transversely (Figs 7, 8, and 9, overleaf).

An initial up-slope from the 15-24 to the 25-34 decade was followed by a gradual decrease in expansion with decreasing age. This pattern was observed in all three planes of measurement, with the exception of circumferential measurements in females. In this case the decrease in expansion began at the 15-24 decade. This exception was thought to be of doubtful significance in view of the size of the natural swing observed between the other means.

The importance of the effect of increasing age on chest expansion was estimated from the following expression:

Age effect $=\frac{\text { Maximal decade mean }- \text { Minimal decade mean }}{\text { Maximal decade mean }} \times 100$

Reference to Table IV (overleaf) shows that the large effect of age in reducing chest expansion (with the exception of measurements in the antero-posterior plane in females) was of approximately the same order $(\bumpeq 50-60$ per cent.) in both sexes in all three planes of expansion.

Table I Normal circumferential chest expansion, by sex and age

\begin{tabular}{|c|c|c|c|c|c|c|c|c|c|c|c|c|c|c|}
\hline \multirow{2}{*}{$\begin{array}{l}\text { Age (yrs) } \\
\text { Sex }\end{array}$} & \multicolumn{2}{|l|}{$15-24$} & \multicolumn{2}{|l|}{$25-34$} & \multicolumn{2}{|l|}{$35-44$} & \multicolumn{2}{|l|}{$45-54$} & \multicolumn{2}{|l|}{$55-64$} & \multicolumn{2}{|l|}{$65-74$} & \multicolumn{2}{|l|}{$75+$} \\
\hline & $M$ & $F$ & $M$ & $F$ & $M$ & $F$ & $M$ & $F$ & $M$ & $F$ & $M$ & $F$ & $M$ & $F$ \\
\hline $\begin{array}{l}\text { No. of subjects } \\
\text { Mean (cm.) } \\
\text { S.D. } \\
\text { Range }\end{array}$ & $\begin{array}{l}23 \\
7 \cdot 01 \\
2 \cdot 00 \\
4 \cdot 00 \\
10 \cdot 00\end{array}$ & $\begin{array}{l}31 \\
5 \cdot 55 \\
1 \cdot 62 \\
3 \cdot 60 \\
9 \cdot 50\end{array}$ & $\begin{array}{l}15 \\
7 \cdot 37 \\
1 \cdot 56 \\
4 \cdot 30 \\
9 \cdot 50\end{array}$ & $\begin{array}{l}12 \\
5 \cdot 46 \\
1.63 \\
3.00 \\
7 \cdot 60\end{array}$ & $\begin{array}{l}12 \\
6 \cdot 56 \\
2 \cdot 07 \\
3 \cdot 40 \\
11 \cdot 80\end{array}$ & $\begin{array}{l}27 \\
4 \cdot 57 \\
0 \cdot 99 \\
2 \cdot 70- \\
7 \cdot 10\end{array}$ & $\begin{array}{l}16 \\
6 \cdot 00 \\
2 \cdot 14 \\
2 \cdot 70 \\
10 \cdot 70\end{array}$ & $\begin{array}{l}26 \\
4 \cdot 82 \\
1 \cdot 29 \\
2 \cdot 60- \\
7 \cdot 50\end{array}$ & $\begin{array}{l}24 \\
5 \cdot 51 \\
1 \cdot 94 \\
1 \cdot 70 \\
9 \cdot 20\end{array}$ & $\begin{array}{l}16 \\
3 \cdot 77 \\
1 \cdot 39 \\
1 \cdot 00 \\
5 \cdot 90\end{array}$ & $\begin{array}{l}13 \\
4 \cdot 00 \\
1 \cdot 27 \\
2 \cdot 00 \\
5 \cdot 70\end{array}$ & $\begin{array}{l}19 \\
3 \cdot 76 \\
1 \cdot 29 \\
1.10 \\
6 \cdot 30\end{array}$ & $\begin{array}{l}8 \\
2 \cdot 81 \\
0 \cdot 73 \\
2.00 \\
4 \cdot 10\end{array}$ & $\begin{array}{l}20 \\
2 \cdot 45 \\
0 \cdot 88 \\
1 \cdot 10 \\
4 \cdot 20\end{array}$ \\
\hline
\end{tabular}

Table II Normal antero-posterior chest expansion, by sex and age

\begin{tabular}{|c|c|c|c|c|c|c|c|c|c|c|c|c|c|c|}
\hline \multirow{2}{*}{$\begin{array}{l}\text { Age (yrs) } \\
\text { Sex }\end{array}$} & \multicolumn{2}{|l|}{$15-24$} & \multicolumn{2}{|c|}{$25-34$} & \multicolumn{2}{|l|}{$35-44$} & \multicolumn{2}{|l|}{$45-54$} & \multicolumn{2}{|l|}{$55-64$} & \multicolumn{2}{|l|}{$65-74$} & \multicolumn{2}{|l|}{$75+$} \\
\hline & $M$ & $F$ & $M$ & $F$ & $M$ & $F$ & $M$ & $F$ & $M$ & $F$ & $M$ & $F$ & $M$ & $F$ \\
\hline $\begin{array}{l}\text { No. of subjects } \\
\text { Mean (cm.) } \\
\text { S.D. } \\
\text { Range }\end{array}$ & $\begin{array}{l}23 \\
2.53 \\
0.76 \\
1.00 \\
4.00\end{array}$ & $\begin{array}{l}31 \\
2 \cdot 13 \\
0 \cdot 63 \\
1 \cdot 50 \\
4 \cdot 50\end{array}$ & $\begin{array}{l}15 \\
3 \cdot 17 \\
1 \cdot 12 \\
1 \cdot 50 \\
5 \cdot 75\end{array}$ & $\begin{array}{l}12 \\
2 \cdot 08 \\
0 \cdot 61 \\
1 \cdot 00 \\
3 \cdot 00\end{array}$ & $\begin{array}{l}12 \\
2 \cdot 50 \\
0 \cdot 85 \\
1 \cdot 25 \\
4 \cdot 50\end{array}$ & $\begin{array}{l}27 \\
1 \cdot 77 \\
0 \cdot 66 \\
0 \cdot 50 \\
3 \cdot 75\end{array}$ & $\begin{array}{l}16 \\
2 \cdot 34 \\
0 \cdot 85 \\
1 \cdot 25 \\
4 \cdot 50\end{array}$ & $\begin{array}{l}26 \\
1.94 \\
0 \cdot 47 \\
1 \cdot 50 \\
3 \cdot 00\end{array}$ & $\begin{array}{l}24 \\
2 \cdot 17 \\
0 \cdot 78 \\
1 \cdot 25- \\
4 \cdot 00\end{array}$ & $\begin{array}{l}16 \\
1 \cdot 72 \\
0 \cdot 55 \\
1 \cdot 00 \\
3 \cdot 25\end{array}$ & $\begin{array}{l}13 \\
1 \cdot 61 \\
0 \cdot 43 \\
1 \cdot 00 \\
2 \cdot 25\end{array}$ & $\begin{array}{l}19 \\
1 \cdot 53 \\
0 \cdot 64 \\
0 \cdot 50 \\
2 \cdot 75\end{array}$ & $\begin{array}{l}8 \\
1 \cdot 78 \\
0 \cdot 51 \\
1 \cdot 00 \\
2 \cdot 50\end{array}$ & $\begin{array}{l}20 \\
1.40 \\
0.49 \\
0.50 \\
2.25\end{array}$ \\
\hline
\end{tabular}

Table III Normal transverse chest expansion, by sex and age

\begin{tabular}{|c|c|c|c|c|c|c|c|c|c|c|c|c|c|c|}
\hline \multirow{2}{*}{$\begin{array}{l}\text { Age (yrs) } \\
\text { Sex }\end{array}$} & \multicolumn{2}{|l|}{$15-24$} & \multicolumn{2}{|l|}{$25-34$} & \multicolumn{2}{|l|}{$35-44$} & \multicolumn{2}{|l|}{$45-54$} & \multicolumn{2}{|l|}{$55-64$} & \multicolumn{2}{|l|}{$65-74$} & \multicolumn{2}{|l|}{$75+$} \\
\hline & $M$ & $F$ & $M$ & $F$ & $M$ & $F$ & $M$ & $F$ & $M$ & $F$ & $M$ & $F$ & $M$ & $F$ \\
\hline $\begin{array}{l}\text { No. of subjects } \\
\text { Mean (cm.) } \\
\text { S.D. } \\
\text { Range }\end{array}$ & $\begin{array}{l}23 \\
2 \cdot 64 \\
0 \cdot 73 \\
1 \cdot 50 \\
5 \cdot 00\end{array}$ & $\begin{array}{l}31 \\
2 \cdot 33 \\
0 \cdot 76 \\
1 \cdot 50 \\
4 \cdot 00\end{array}$ & $\begin{array}{l}15 \\
2 \cdot 98 \\
0 \cdot 86 \\
1 \cdot 50 \\
4 \cdot 75\end{array}$ & $\begin{array}{l}12 \\
2 \cdot 66 \\
0 \cdot 78 \\
1 \cdot 50 \\
4 \cdot 25\end{array}$ & $\begin{array}{l}12 \\
2 \cdot 96 \\
1 \cdot 25 \\
0 \cdot 00 \\
4 \cdot 25\end{array}$ & $\begin{array}{l}27 \\
2 \cdot 41 \\
0 \cdot 67 \\
1 \cdot 25- \\
4 \cdot 25\end{array}$ & $\begin{array}{l}16 \\
2 \cdot 58 \\
0 \cdot 82 \\
1 \cdot 25 \\
4 \cdot 25\end{array}$ & $\begin{array}{l}26 \\
2 \cdot 33 \\
0 \cdot 81 \\
0 \cdot 75- \\
4 \cdot 00\end{array}$ & $\begin{array}{l}24 \\
2 \cdot 27 \\
1 \cdot 08 \\
1 \cdot 00 \\
4 \cdot 50\end{array}$ & $\begin{array}{l}16 \\
1 \cdot 83 \\
0 \cdot 66 \\
0 \cdot 00- \\
2 \cdot 50\end{array}$ & $\begin{array}{l}13 \\
1 \cdot 73 \\
0 \cdot 74 \\
0 \cdot 25- \\
2 \cdot 25\end{array}$ & $\begin{array}{l}19 \\
1 \cdot 85 \\
0 \cdot 77 \\
0 \cdot 25- \\
3 \cdot 00\end{array}$ & $\begin{array}{l}8 \\
1 \cdot 47 \\
0 \cdot 74 \\
0 \cdot 00 \\
2 \cdot 25\end{array}$ & $\begin{array}{l}20 \\
0 \cdot 96 \\
0 \cdot 53 \\
0 \cdot 50 \\
2 \cdot 00\end{array}$ \\
\hline
\end{tabular}



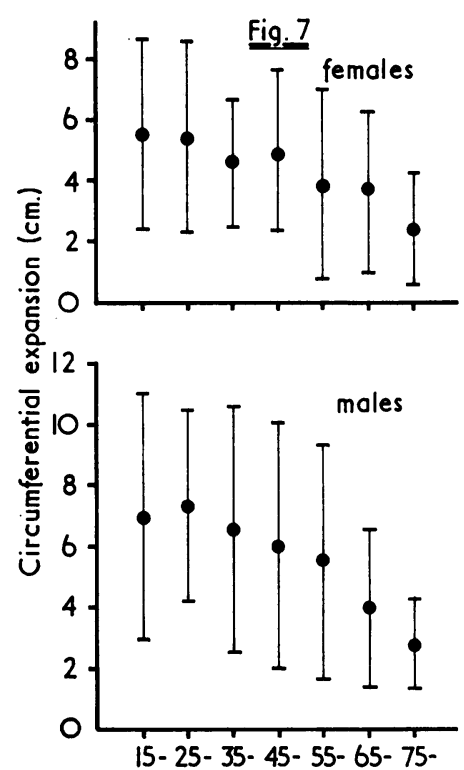

Age in decodes

FIG. 7 Circumferential chest expansion in males and females. Mean expansion \pm 2 S.D. plotted against age in decades

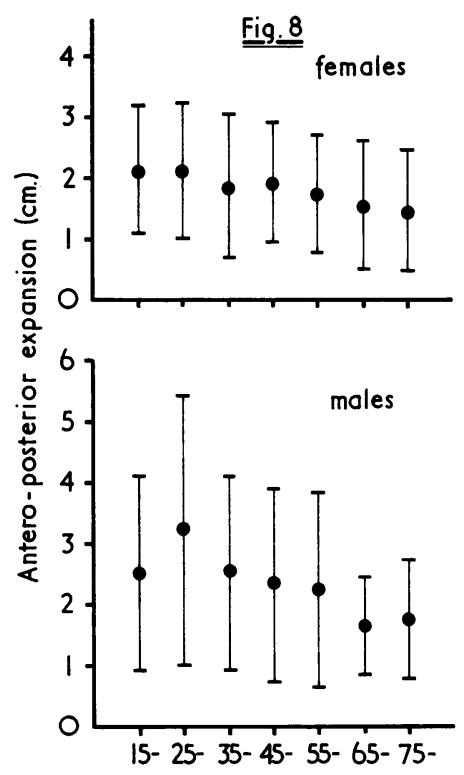

FIG. 8 Antero-posterior chest expansion in males and females. Mean expansion \pm 2 S.D. plotted against age in decades

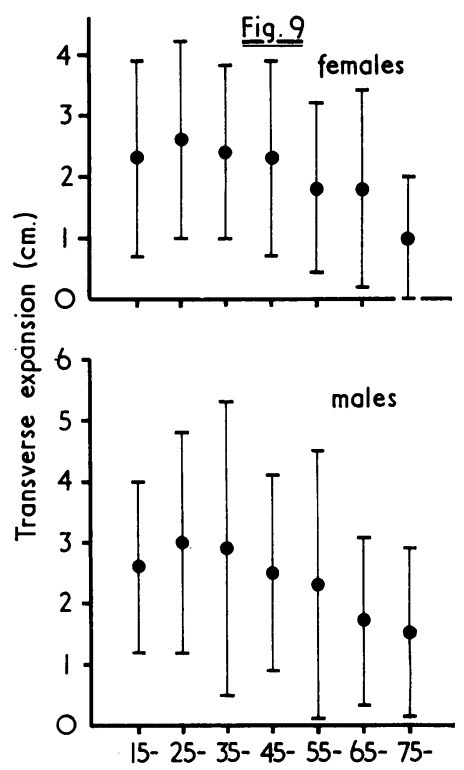

FIG. 9 Transverse chest expansion in males and females. Mean expansion \pm 2 S.D. plotted against age in decades
Table IV Percentage reduction in chest expansion due to age

\begin{tabular}{lll}
\hline Type of measurement & \multicolumn{2}{c}{ Reduction due to age (per cent.) } \\
\cline { 3 - 3 } & $M$ & $F$ \\
\hline Circumferential & 61 & 55 \\
Transverse & 50 & 63 \\
Antero-posterior & 49 & 34 \\
\hline
\end{tabular}

(b) As shown in Figs 10,11 and 12 (opposite), male expansion exceeded female expansion at each decade in all three planes of measurement with the exception of a small female excess of doubtful significance in subjects of the 65-74 decade measured transversely.

The magnitude of the effect due to sex was assessed by the following ratio:

Sex effect $=\frac{\text { Overall* male mean }- \text { Overall female mean }}{\text { Overall male mean }} \times 100$

As shown in Table V, the extent of the sex effect in reducing chest expansion, although sizeable, was not of the same order as that due to age. Circumferential and antero-posterior expansion were about 20 per cent. less in females than males. When measurep transversely expansion was 13 per cent. less in females.

- Overall mean signifies average expansion of all decades for that particular sex.
Table $\mathrm{V}$ Percentage reduction in chest expansion due to sex

\begin{tabular}{|c|c|}
\hline Type of measurement & $\begin{array}{l}\text { Reduction due to sex (per cent.) } \\
(F<M)\end{array}$ \\
\hline $\begin{array}{l}\text { Circumferential } \\
\text { Transverse } \\
\text { Antero-posterior }\end{array}$ & $\begin{array}{l}21 \\
13 \\
22\end{array}$ \\
\hline
\end{tabular}

(c) In all decades in both sexes and in all three planes of expansion (Figs 7, 8, and 9), a wide range of normal values (mean \pm 2 S.D.) was observed. On the whole the greatest variations were recorded for transverse measurements and the smallest for circumferential measurements.

(d) The most important observation concerned the way in which the normal scatter of circumferential expansion in both sexes extended well below the $2.5 \mathrm{~cm}$. borderline stipulated by the New York symposium (Bennett and Wood, 1968) to represent the division between normal and abnormal expansion.

\section{(2) CHEST EXPANSION IN DISEASE}

Expansion was measured in three abnormal groups comprising patients with ankylosing spondylitis, chronic chest disease, and obesity. The spondylitic patients were examined in order to test the traditional observation that expansion is decreased in this disease. Measurements on patients with chest disease and obesity were undertaken to assess the 

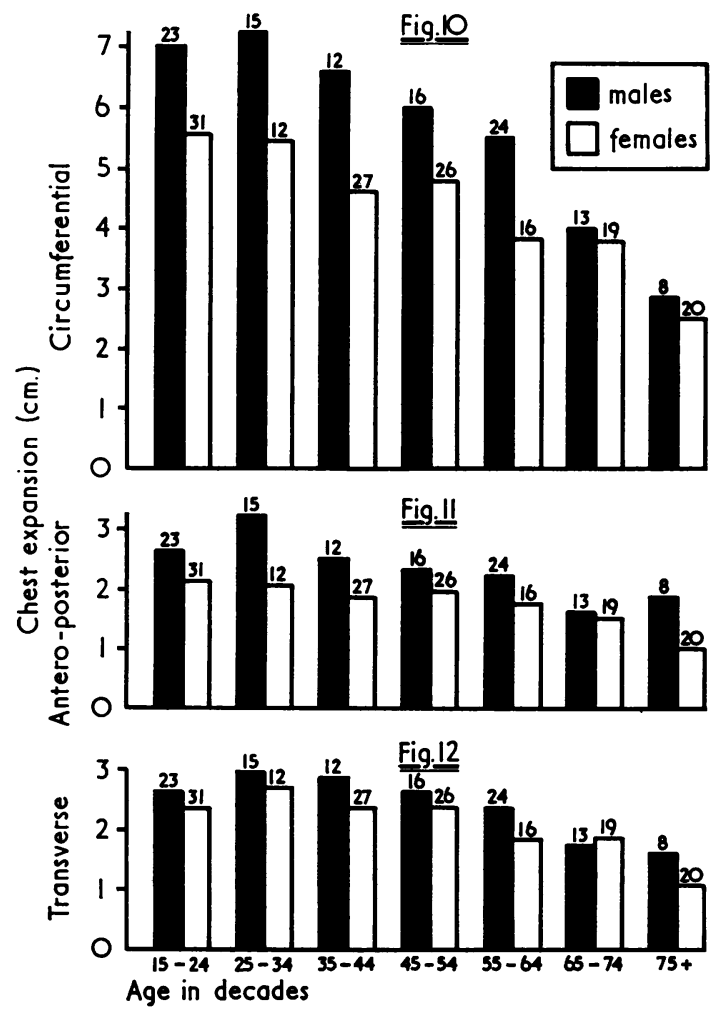

FIG. 10 Male predominance of circumferential chest expansion

FIG. 11 Male predominance of antero-posterior chest expansion

FIG. 12 Male predominance of transverse chest expansion

specificity of diminished expansion as a diagnostic feature of ankylosing spondylitis. The results were expressed in terms of $(a)$ the percentage of total subjects in each disease group in whom chest expan- sion was below the mean and $(b)$ the percentage in whom expansion was less than the 2 S.D. limit (Table VI).

Reference to Fig. 13, which illustrates the percentage in whom expansion was below the mean, shows the considerable decrease in chest expansion, particularly circumferentially and transversely, in patients with ankylosing spondylitis. A slightly smaller but significant $(P<0.01)$ decrease was observed in patients with chest disease, the effect being more marked in females throughout the different planes of measurement. Obese subjects were found to have a significantly diminished expansion in the antero-posterior plane $(\mathrm{P}=\mathbf{0 . 0 2}$ for males; $P=0.006$ for females) and a highly significant decrease in females measured circumferentially $(P=$ $10^{-4}$ ). The other measurements, however, were not significantly decreased by obesity. It should be noted that a high proportion of patients (in all three diagnostic categories) who exhibited normal chest expansion had pursued or were still pursuing some form of athletic activity.

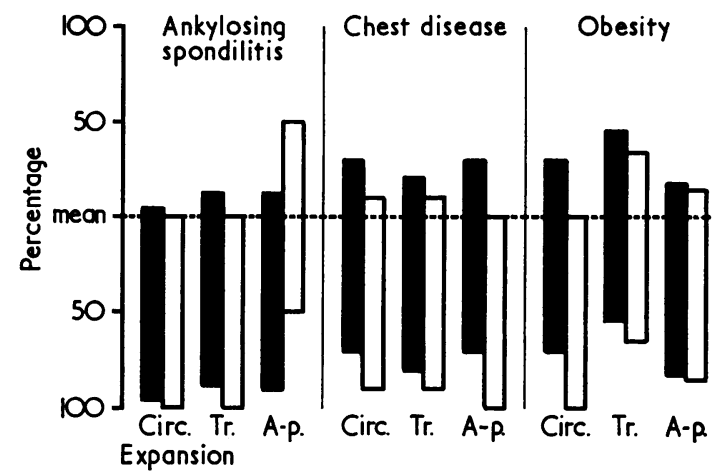

FIG. 13 Effect of ankylosing spondylitis, chronic chest disease, and obesity on chest expansion

Table VI Percentage of subjects with various diseases in whom chest expansion was below the mean or less than $2 S . D$. from the mean

\begin{tabular}{|c|c|c|c|c|c|c|c|c|c|}
\hline \multirow[t]{3}{*}{ Disease } & \multirow{2}{*}{\multicolumn{2}{|c|}{ No. of cases }} & \multicolumn{7}{|c|}{ Measurement } \\
\hline & & & \multicolumn{2}{|c|}{$\begin{array}{l}\text { Circumferential } \\
\text { (per cent.) }\end{array}$} & \multicolumn{2}{|c|}{$\begin{array}{l}\text { Transverse } \\
\text { (per cent). }\end{array}$} & \multicolumn{2}{|c|}{$\begin{array}{l}\text { Antero-posterior } \\
\text { (per cent.) }\end{array}$} & \multirow[t]{2}{*}{ Difference* } \\
\hline & $M$ & $F$ & $M$ & $F$ & $M$ & $F$ & $M$ & $F$ & \\
\hline \multirow[t]{2}{*}{ Ankylosing spondylitis } & 28 & 9 & 96 & 100 & 87 & 100 & 89 & 50 & $<$ mean \\
\hline & & & 39 & 55 & 11 & 33 & 11 & 11 & $<2$ S.D. from mean \\
\hline \multirow[t]{2}{*}{ Chronic chest disease } & .22 & 9 & 72 & 88 & 81 & 88 & 72 & 100 & $<$ mean \\
\hline & & & 5 & 33 & 9 & 44 & 5 & 33 & $<2$ S.D. from mean \\
\hline \multirow[t]{2}{*}{ Obesity } & 13 & 20 & 60 & 100 & 53 & 65 & 83 & 85 & $<$ mean \\
\hline & & & 0 & 15 & 0 & 5 & 0 & 19 & $<2$ S.D. from mean \\
\hline
\end{tabular}

- Subjects exactly on the mean excluded. 


\section{Discussion}

As the data obtained by the present study represents the first attempt to establish a normal range of chest expansion in an unselected group of normal subjects it is impossible to attempt a strictly analogous comparison with previous studies. These earlier reports were based on highly selected populations with regard to both sex and age. Such populations included schoolboys (Wood, 1970), male and female physical education students (Bradbury, Brooke, and Maclock, 1969), and male medical students (Malone, 1904). Furthermore, the surface markings used to identify the level of measurement varied from nipple level (Hart and Maclagan, 1955; Hunter and Bomford, 1963) to 4th intercostal space (Bennett and Wood, 1968; Bradbury and others, 1969), and frequently no specific level of measurement was reported (Malone, 1904; Durrigl, Mezulic, Androic, and Vitaus, 1965; Wood, 1970). Broadly speaking, however, numerical data for both circumferential (Hart and Maclagan, 1955; Hunter and Bomford, 1963; Durrigl and others, 1965; Bradbury and others, 1969; Wood, 1970) and diametric expansion (Malone, 1904; Bradbury and others, 1969) compare reasonably well with the results obtained from the present investigation.

Attention has been drawn to the important effect of age and sex on chest expansion. The practical significance of these age and sex-dependent phenomena stems from the possibility of false positive diagnosis of ankylosing spondylitis if no correction were made for these characteristics. A further feature of considerable importance concerns the surprisingly wide variation of measurements of normal expansion at each decade. This normal scatter was so extensive that, if a horizontal limit at the $2.5 \mathrm{~cm}$. level (as recommended by the New York symposium) were to be drawn across the series of vertically disposed normal scatter lines (representing the range of normal measurement at each decade), a high proportion of normal subjects (more females than males) after middle age would be falsely diagnosed as having abnormal chest mobility. This is clearly a diagnostically invalid situation and indicates the unreality of adopting such an inflexible parameter to measure a biological movement.

The study of the effect of certain diseases on chest expansion has confirmed objectively the traditional claim that chest movement is diminished in ankylosing spondylitis. It has also shown that other conditions, such as chronic chest disease and obesity, may also significantly limit mobility at this site. The fact that diseases other than spondylitis may reduce expansion seriously undermines the value of chest mobility as a reliable criterion for the diagnosis of ankylosing spondylitis. In this sense, therefore, chest expansion is not a particularly specific sign of spondylitis. However, applying 'specificity' as defined by Bennett and Burch (1968) as 'the capacity of a test to give a negative response if the disease is absent',

$$
\frac{\text { True negatives }}{\text { True negatives }+ \text { False positives }} \times 100
$$

chest expansion may be regarded as highly specific (Moll, 1971a). There are, therefore, two facets of specificity to be considered: (a) low specificity due to the high incidence of false positive expansion measurements in diseases other than spondylitis (such as chronic chest disease and/or obesity) and

(b) high specificity due to the low incidence of false positives in normal individuals.

A further point concerns the place of chest expansion in the recently outlined New York clinical criteria for spondylitis. Table VII shows that, in the presence of advanced sacroiliitis (bilateral grade $3 / 4$ ), chest expansion alone is sufficient to merit a diagnosis of 'definite' ankylosing spondylitis. Concerning lower grades of sacro-iliitis, however, chest expansion must be associated with thoraco-lumbar pain in order to constitute such a diagnosis. In view of the central importance of chest expansion in this scheme and the high prevalence in the United Kingdom of diseases likely to result in false positive fulfilment of this criterion (chronic bronchitis and/or obesity), it is suggested that the diagnosis of anything but obvious ankylosing spondylitis should be regarded with con siderable caution, particularly if unequivocal radiological evidence is not present. Moreover, even considering the addition of back pain (criterion 2) to chest expansion (criterion 3 ), the high prevalence of lumbago due to other conditions such as disorders of the lumbar disc (Wood, 1971) renders even this clinical combination somewhat unreliable as a specific diagnostic index.

Table VII Definition of definite and probable ankylosing spondylitis according to the New York criteria (Bennett and Wood, 1968)

\section{Clinical criteria}

(1) Limitation of motion of the lumbar spine in all three planes - anterior flexion, lateral flexion, and extension

(2) History of the presence of pain at the dorso-lumbar junction or in the lumbar spine

(3) Limitation of chest expansion to $1 \mathrm{in} .(2.5 \mathrm{~cm}$.) or less measured at the level of the fourth intercostal space

Definite ankylosing spondylitis

(1) Grade 3-4 bilateral sacro-iliitis with at least one clinical criterion or

(2) Grade 3-4 unilateral or grade 2 bilateral sacro-iliitis with clinical criterion 1 or with both clinical criteria 2 and 3 .

Probable ankylosing spondylitis

Grade 3-4 bilateral sacro-iliitis without any clinical criteria.

In order to obviate these problems of diagnosis, it is suggested that clinical observation of the chest be sup- 
plemented by radiological assessment of diaphragmatic movement. This suggestion is derived from the traditional observation (Hart, Robinson, Allchin, and Maclagan, 1949; Hart and Maclagan, 1955) that diaphragm movement remains remarkably normal in spondylitis compared with the progressive immobility of this structure which occurs in emphysema. The relatively normal pattern of diaphragm mobility in spondylitis has recently been confirmed objectively by one of us (Moll, 1971b). The large variation between diaphragm excursion in spondylitis and emphysema compared with normal values is shown in Table VIII and Fig. 14.

Table VIII Comparison of diaphragm mobility in normal subjects, cases of emphysema and cases of ankylosing spondylitis

\begin{tabular}{lll}
\hline Normal & Emphysema & $\begin{array}{l}\text { Ankylosing } \\
\text { spondylitis }\end{array}$ \\
\cline { 1 - 1 } $\begin{array}{l}5-10 \mathrm{~cm} . \\
(\text { Simon, 1962) }\end{array}$ & $\begin{array}{l}<\mathrm{cm} . \\
\text { (Simon, 1962) }\end{array}$ & $\begin{array}{l}4 \cdot 5-6 \cdot 5 \mathrm{~cm} . \\
\text { (Moll, 1971b) }\end{array}$ \\
\hline
\end{tabular}

In view of the comparable pattern of behaviour of chest expansion in all three planes of mobility, for ordinary clinical and epidemiological purposes, it should be sufficient to measure expansion in one plane only. It is suggested that circumferential measurements be retained as the routine method for measuring chest expansion but that in obese subjects or those with large pendulous breasts examination should be supplemented by caliper measurements.

Finally, it is concluded that chest expansion, although failing in many respects as a reliable diagnostic index of ankylosing spondylitis, should nevertheless be regarded as a valuable adjunct in the therapeutic and prognostic assessment of these patients.

\section{Summary}

(1) Influenced by the importance of chest expansion as a clinical criterion of ankylosing spondylitis, an objective study of 262 subjects (111 males and 151 females) was undertaken to establish for the first time a normal range of values for this movement.

(2) A separate study was carried out in order to assess the effect of various diseases on chest expansion, including ankylosing spondylitis (37 patients), chronic chest disease ( 31 patients), and obesity (33 patients).

(3) Measurements were made circumferentially with a centimetre tape-measure and diametrically (in the antero-posterior and transverse planes) by means of a special caliper.

(4) Measurements of normal subjects revealed the following:

(a) Mean expansion, after an initial increase, showed a gradual but considerable ( $\bumpeq 50-60$ per cent.) decrease with advancing age.

(b) Male expansion exceeded female expansion by 13-22 per cent.

(c) A wide scatter of normal values was observed at all decades.

(5) The separate study confirmed the restrictive effect of ankylosing spondylitis on chest expansion and also revealed a similar but less marked effect due to chronic chest disease and obesity.

(6) It was concluded that:

(a) In view of the extensive normal scatter of expansion and its wide variation with age and sex, the conventional and rigid $2.5 \mathrm{~cm}$. borderline between normal and abnormal measurements (New York symposium, 1966) should be abandoned.

(b) Considering the importance of age, sex, and diseases other than spondylitis in decreasing chest expansion, allowance should be made for these factors in order to avoid a false-positive diagnosis of ankylosing spondylitis.

(c) Chest expansion is too non-specific to be useful as an accurate diagnostic index of spondylitis. However, its utility could be enhanced by supplementing clinical measurement by radiographic observation of diaphragm excursion in cases of diagnostic doubt.

(d) The comparable patterns of behaviour of chest expansion in all three planes of mobility indicate that for usual purposes circumferential measurement alone should be adequate. However, in obese or largebreasted individuals, examination should be supplemented by diametric measurement.

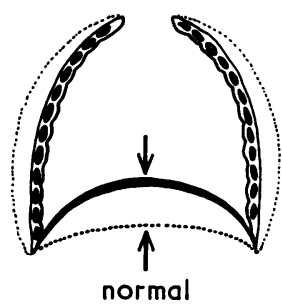

2

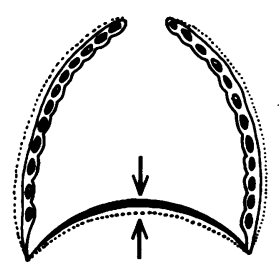

chest disease

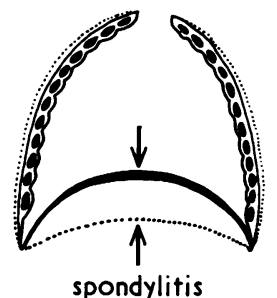

spondylitis
FIG. 14 Patterns of chest wall/diaphragm mobility in normal subjects, and in patients with chronic chest disease (principally emphysema) and ankylosing spondylitis 
We should like to thank Mrs. E. W. Davey and Miss K. E. Rowe for technical help and Mrs. B. Antcliffe and Mrs. B. Gordon for secretarial assistance. The helpful co-operation of both the normal subjects and the patients in the various diagnostic groups is gratefully acknowledged.
Dr. H. G. Bevans and Mr. R. Maguire provided helpful statistical advice. The study could not have been under- 3 taken without financial support from the West Riding Medical Trust.

\section{References}

Bennett, P. H., AND BURCh, T. A. (1968) In 'Population Studies of the Rheumatic Diseases,' Proc. 3rd International Symposium, New York, 1966, ed. P. H. Bennett and P. H. N. Wood, pp. 305-313. Int. Congr. Ser. No. 148, Excerpta Medica Foundation, Amsterdam

Bennett, P. H., AND Wood, P. H. N. (eds) (1968) 'Population Studies of the Rheumatic Diseases', as above, p. 456. Excerpta Medica Foundation, Amsterdam

BradbuRY, I., BroOKe, J. D., AND MAClOCK, M. (1969) Phys. Ed., 61, 64 (A comparison of the Rees-Eysenck index of male body shape with the Rees index of female body shape in males and females)

CRADDOCK, D. (1969) 'Obesity and its Management,' p. 3. Livingstone, Edinburgh

Durrigl, T., Mezulic, L., ANDroic, S., AND Vitaus, M. (1965) Rheumatism, 21, 79 (Ankylosing spondylitisclinical examination)

Hart, F. Dudley, and Maclagan, N. F. (1955) Ann. rheum. Dis., 14, 77 (Ankylosing spondylitis; a review of 184 cases)

—_, Robinson, K. C., Allchin, F. M., and Maclagan, N. F. (1949) Quart. J. Med., 18, 217 (Ankylosing spondylitis)

HaRtung, E. F. (1954) In 'The History and Conquest of Common Diseases', ed. W. R. Bett, p. 133. University of Oklahoma Press, Norman, Okla

Hunter, D., AND BOMFord, R. R. (1963) 'Hutchison's Clinical Methods,' 14th ed., p. 186. Cassell, London

JoNEs, F. WooD (ed.) (1946) 'Buchanan's Manual of Anatomy', 7th ed., p. 1052. Baillière, Tindall and Cox, London

Kellgren, J. H., JefFrey, M. R., AND BALl, J. (1963). The Epidemiology of Chronic Rheumatism', vol. 1, p. 326. Blackwell, Oxford

MaLONE, F. F. (1904) J. Amer. med. Ass., 43, 783 (Relation of chest contour to lung capacity)

Moll, J. M. H. (1971a) 'A Family Study of Psoriatic Arthritis.' D. M. Thesis, University of Oxford (1971b). An objective study of diaphragm movement in patients with ankylosing spondylitis. In preparation

Simon, G. (1962) 'Principles of Chest X-ray Diagnosis,' 2nd ed., p. 110. Butterworths, London

Wood, A. G. (1970) Brit. J. phys. Educ., 1, 70 (Rugger team analysed)

Wood, P. H. N. (1971) Brit. med. Bull., 27, 82 (Rheumatic complaints) 